\title{
Cable-stayed bridges chatter performance analysis
}

\author{
Guo Qinghua \\ Hubei Communications Technical College, Wuhan, China
}

Keywords: Cable-stayed bridge, tremor performance, ANSYS, stress analysis

\begin{abstract}
With the development of transport, compared with ordinary cable-stayed bridge cable-stayed bridge because of its convenience, appearance, economical characteristics of the construction, in the construction of roads, bridges in the city has been rapid application, but because of the structural rigidity of special bridge requirements, so now one of the few cablestayed bridges has been built. Part of the existing cable-stayed bridge features to summarize, found common ground stiffness, a large proportion of the live load, and by information found in the study of large-span cable-stayed bridge wind performance gap by almost belong. However, with the development of road transport services, more and more large-span, and with spans increase wind loads on the beam impact has become a non-negligible factor. Taking a cable-stayed bridge in the background, its research performance chatter, and the first use of ANSYS software and the numerical simulation of the effect of wind load stress analysis for the construction of the latter part provides a theoretical basis.
\end{abstract}

\section{Introduction}

Cable-stayed bridge is made of bending of the beam, the tension of the cable and bearing tower combining a structured system. It is the main beam with many cable-stayed bridge tower anchored directly on a bridge, also known as cable-stayed bridge. Its form can be seen as the force with multispan cable instead of buttress elastic support continuous beam. Modern span cable-stayed bridge is moving, highly flexible direction. In China, the introduction of cable-stayed bridge section later, but its rapid development from 2000 to 2001, Wuhu Yangtze River Bridge in Fuzhou and Zhangzhou readiness have been built, to become China's first road-rail analysis of steel and concrete cable-stayed bridge stiffening portion section box girder bridge, which opened the prelude to the part of cablestayed bridge construction and development of our country ${ }^{[1]}$. After Tongan Silver Lake Bridge, Lanzhou Xiaoxihu Yellow River Bridge, along with Sai Van Bridge is completed, which provides a realistic basis for the cable-stayed bridge part superior structural performance, good economic indicators, as part of the cable-stayed bridge in the country further the development of a sophisticated construction methods, improve the management experience, but also those for the analysis of mechanical characteristics of the cable-stayed bridge section provides a wealth of scientific data ${ }^{[2]}$.

\section{Earthquake Mechanisms}

Cable-stayed bridge aeroelastic response in turbulent wind action is the result of many factors working together. Bridges absorb energy from the wind, self-excited vibration, cable-stayed low stiffness, vibration get excited, which in turn affect the air flow field the formation mechanism of the 
interaction of wind and small structure when the impact caused by the air force structure forced vibration; when the impact is large, by the structural vibration feedback control of the air force structure leads to a self-excited vibration of air flow rate on the different degrees of freedom of movement ${ }^{[3]}$. amplitude and phase relation between the structure so that the air flow constantly draw energy (the energy is greater than the structural damping dissipated energy), this form of self-excited oscillation is divergent flutter purpose is to avoid wind-resistant design dangerous vibration divergent, the critical wind speed greater than the design wind speed, while the amplitude control within an acceptable range ${ }^{[4]}$.

(1) Classical Flutter Coupling Theory

In 1935, Theodorson potential theory obtained by acting on the vibrating plate unsteadies air force one tablet flutter theory ${ }^{[5]}$. In 1948, Bleich asked to consider additional lift bridge end faces on both sides of the scroll key influence can be corrected by successive approximation method to calculate a reasonable suspension bridge flutter critical wind speed, which was founded by the suspension of the two degrees of freedom flutter classical theory ${ }^{[6]}$. until 1967, K bppel Thiele and eventually solving the above-described steps compiled into the program, drawn Connaught desert FIG directly solve critical flutter wind speed due to the damping effect can be safely ignored biased, 1976, Vanderut plate coupled flutter in the study when the critical flutter wind speed, wind speed and bending and torsion translation found near-linear relationship between frequency ratio, a group of linear parameters affecting the rest of the formed can be approximated as the intersection at one point then regressed flat flutter critical wind speed approximate formula:

$$
U_{\text {cr }}=\eta_{s} \eta_{a}[1+(\varepsilon-0.5) \sqrt{0.72 \mu(r / b)}] \omega_{h} b
$$

(2) Torsional Flutter Separated Flow Theory

Classical theory ignores the coupled flutter flow separation, because the actual cross-section is not a bridge over the bluff, with the potential flow theory can not describe the unsteady force ${ }^{[7]}$. In $1971 \mathrm{R}$. Scanlan made through a special wind tunnel tests measured at small amplitude linear unsteady aerodynamic parameters (flutter derivatives) to build a linear model and based on strip theory, to determine the direction perpendicular to the axis of the two-dimensional bridge flutter equation ${ }^{[8]}$ :

$$
\begin{gathered}
L_{h}=\frac{1}{2} \rho U^{2}(2 B)\left(K H_{1}^{*} \frac{\dot{h}}{U}+K H_{2}^{*} \frac{\dot{\alpha} B}{U}+K^{2} H_{3}^{*} \alpha\right) \\
M_{a}=\frac{1}{2} \rho U^{2}\left(2 B^{2}\right)\left(K A_{1}^{*} \frac{\dot{h}}{U}+K A_{2}^{*} \frac{\dot{\alpha} B}{U}+K^{2} H_{3}^{*} \alpha\right) \times \\
{\left[\begin{array}{cc}
\mathrm{m} & O \\
o & J
\end{array}\right]\left[\begin{array}{c}
\dot{h} \\
\ddot{\alpha}
\end{array}\right]+\left[\begin{array}{cc}
C_{h} & 0 \\
0 & C_{\alpha}
\end{array}\right]\left[\begin{array}{c}
\dot{h} \\
\dot{\alpha}
\end{array}\right]+\left[\begin{array}{cc}
K_{h} & 0 \\
0 & K
\end{array}\right]\left[\begin{array}{l}
\dot{h} \\
\alpha
\end{array}\right]=\left[\begin{array}{l}
L \\
M
\end{array}\right]}
\end{gathered}
$$

\section{Dynamic Model}

Wind power stability in its cable-stayed bridge is built on the dynamic characteristics of the infrastructure, before making wind analysis need to get a first-order vertical bend cable-stayed bridge, the first torsional vibration mode and the first order of scoliosis vibration mode, because these modes of wind-induced vibration in the cable-stayed bridge, such as flutter, buffeting plays an extremely important role ${ }^{[9]}$. Therefore, in the study of dynamic characteristics of cable-stayed bridge, the need to establish the spatial calculation model analysis and calculation.

We elastic dynamics model of large-span overpass, we must first establish the Pan function, usually using the variational principle to the establishment of the Pan-function basis Elastodynamics numerical methods, by their stationary condition can be obtained elastic dynamics equations and boundary conditions

Usually we set the initial conditions for the $u(x, o)=u_{0}(x), u\left(x, t_{1}\right)=u_{1}\left(x_{1}\right)$, wherein, $u_{0}(x)$ and $u_{1}(x)$ is a given function, we study the above geometric equations and physical 
equations reservations through their established and boundary conditions to calculate satisfies the above equation with the possibility of motion $^{[10]}$. We have established by Hamilton variational principle to carry out, first of all we put in the value equation established conditions are met, the variational principle which we stated as follows:

$$
\delta \int_{0}^{1} L d t=\delta \int_{0}^{1}(K-U) d t=0
$$

Among them, the above formula for the Lagrange function L, $K=\frac{1}{2} \int_{v} \rho \frac{d u_{i}}{d t} \frac{d u_{i}}{d t} d V$ is the kinetic energy of the system; $U=\int_{V}\left(\sigma_{i j} \varepsilon_{i j} / 2-\rho f_{i} u_{i}\right) d V-\int_{S \sigma} p_{i} u_{i} d S$ potential energy for the system.

We will be substituted into the formula $\mathrm{K}$ and $\mathrm{Y}$, and one by one by the variational calculation, you can get the following equation:

$$
\int_{0}^{1}\left[\int_{v}\left(-\rho u_{i}+\sigma_{i j, j}+\rho f_{i}\right) \delta u_{i} d V+\int_{S \sigma}\left(-p_{i}+p_{i}\right) \delta u_{i} d S\right] d t=0
$$

Since $\left(\sigma_{i j}\right)_{, j}=\sigma_{i j, j} \delta u_{j}+\sigma_{i j} \delta u_{i, j}, p_{i}=\sigma_{i j} n_{j}$, into the formula, and apply the divergence theorem:

$$
\delta \prod=\int_{0}^{1}\left[\int_{v}\left(\rho u_{i}+\sigma_{i j, j}-\rho f_{i}\right) \delta u_{i} d V-\int_{S \sigma} p_{i} \delta u_{i} d S\right] d t=0
$$

Second Order on structural dynamic response after finite element discretization obtain ordinary differential equations.

(1) Model material parameters selected

Bridge a total length of $1460 \mathrm{~m}$ total of seven cross. The $820 \mathrm{~m}$ span steel concrete composite cable stayed bridge. Cross the main beam using flat streamlined steel box girder, main beam full width $28 \mathrm{~m}$ (including nozzle), main beam centerline height $3.5 \mathrm{~m}$, using inverted Y-shaped tower of reinforced concrete tower, tower $221.6 \mathrm{~m}$, using cable-stayed fan-shaped space double cable plane cable-stayed arrangement, the use of parallel wire strands, each of the 21 pairs of cable plane cable, 88 pairs of fullbridge (176), side span from standard cable $8 \mathrm{~m}$, cross standard cable from $15 \mathrm{~m}$. Table 1 shows the material properties.

Table 1. Material parameters

\begin{tabular}{|l|c|c|c|c|}
\hline \multicolumn{1}{|c|}{ member } & Main girder & Pylons & Stay Cables & Variable pier \\
\hline Elastic Modulus $\left(\mathrm{N} / \mathrm{m}^{2}\right)$ & $2.1 \mathrm{E}+11$ & $3.45 \mathrm{E}+10$ & $1.95 \mathrm{E}+11$ & $3.25 \mathrm{E}+10$ \\
\hline Density $\left(\mathrm{kg} / \mathrm{m}^{3}\right)$ & 7850 & 2600 & 7850 & 2600 \\
\hline Poisson's ratio $(\mu)$ & 0.3 & 0.17 & 0.3 & 0.17 \\
\hline
\end{tabular}

According to the parameter values, finite element analysis, finite element model shown in Figure 1. 


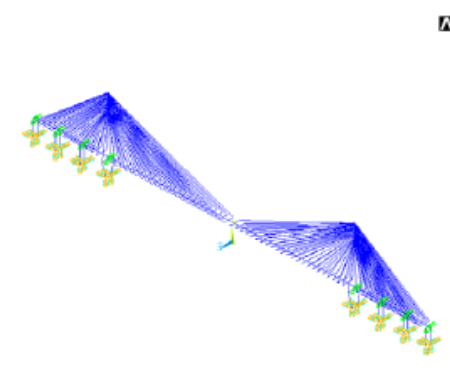

Figure 1. Double main beam model

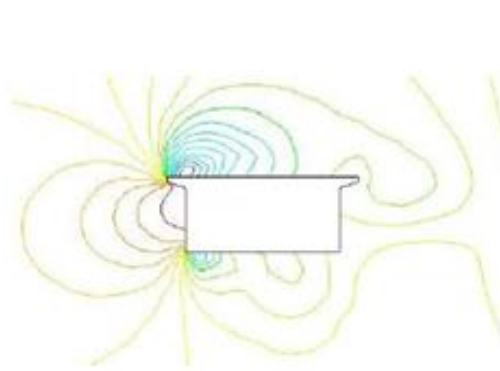

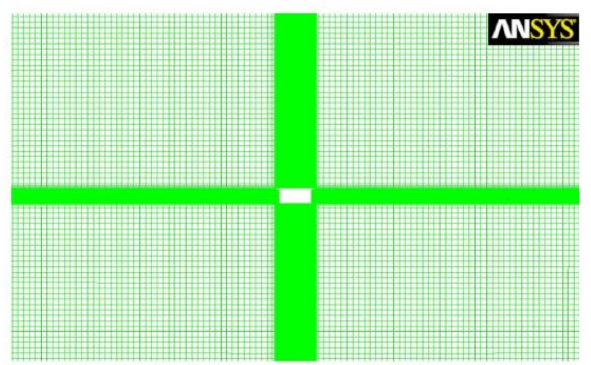

Figure 2. Finite element model of the main beam section

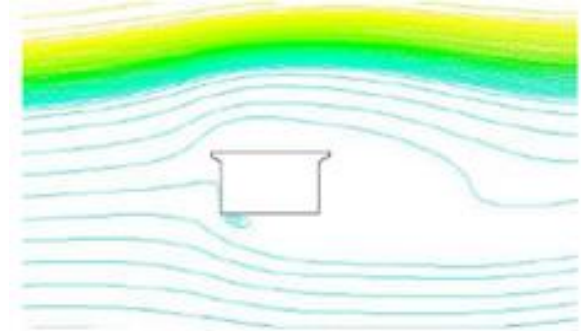

Figure 3. Flow field pressure profile

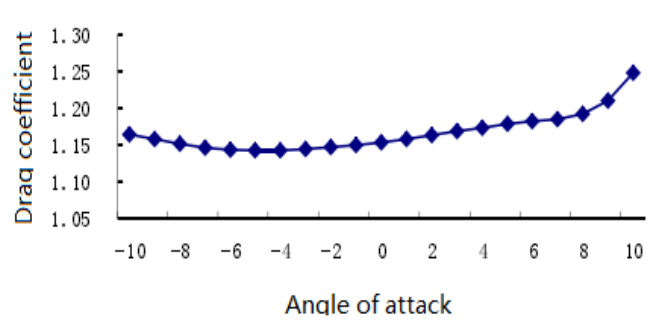

Figure 5. Drag coefficient

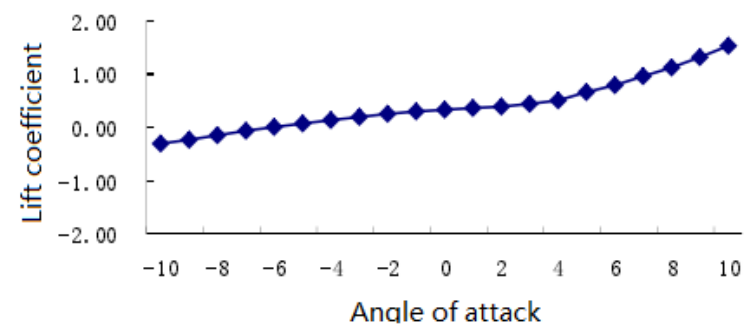

Figure 6. Lift coefficient

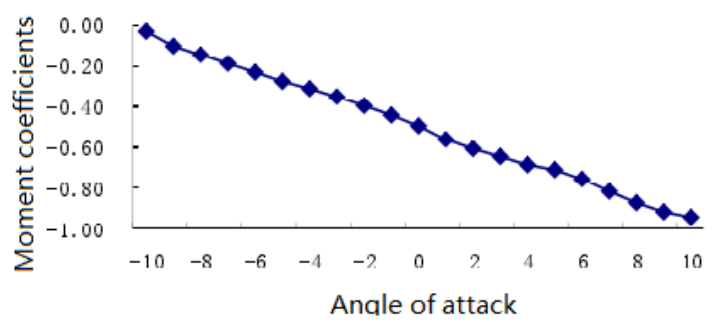

Figure 7. Moment coefficients

According to different angles of attack we can directly see the effect of the wind section of the flow field around the pressure distribution and flow field flow chart main beam at different angles of attack - wind, beam upper and lower surfaces, front and rear surface pressure and flow field flow lines are undergoing different changes. Large wind attack angle of the upper and lower surfaces of the beam cross-section relative to the uneven distribution of pressure, close to the inlet portion of the beam cross-section vary widely, especially in the straight edges and corners.

Through the above theory and data analysis, it can be seen in the cross-sectional shape of the cablestayed bridge across the third force coefficient with the beam cross section, and the variation of wind speed wind angle of attack has a direct relationship. The middle section of the drag coefficient is less affected, the change is relatively stable. The lift coefficient greater impact and torque coefficient by 
the wind changes the angle of attack, especially in the wind attack angle of between -10 degrees to -7 degrees, its value changes were more than $23 \%$.

\section{References}

1. Cheng S,Irwin P A, Jakobsen J B et al. Divergent motion of cables exposed to skewed wind. In: Proceedings of the 5th International Symposium on Cable Dynamics, Santa Margherita, 2013, 271-278

2. Larose G L,Jakobsen J B, Savage M G etl. Wind tunnel experiments on an inclined and yawed stay cable model in the critical Reynolds number range. In: Proc of the 5th International Symposium on Cable Dynamics, Santa Margherita, 2013, 279-286

3. Kazama K, Yamada H, Miyata T. Wind resistant design for long span suspension bridges. Journal of Wind Engineering and Industrial Aerodynamics, 2005, 54:65-74

4. Zhu Zhiwen Numerical Methods and Application of Bridge Wind Effect [D] Changsha: Central South University, 2002.

5. Hui Lin. Suspension Flutter Frequency Domain Analysis and construction stage Study on Aerodynamic Stability [D]., Southwest Jiaotong University, 2003.

6. R. H. Scanlan, R. Rosenbaum. Aircraft vibration and flutter [M].New York, Macmillan,1951;Dover,1968.

7. Du Qing, Zhang Xianmin. Bridges and other reinforced concrete structures dynamic finite element model updating Highway and Transportation Research, 2006, 23 (1): 60-63

8. Ding Quanshun. Long-span bridges coupled shaking vibration response of refined analysis [D] Shanghai: Tongji University, 2001.

9. Dong exquisite Oversized span cable-stayed bridge Wind stability study the whole process [D]. Zhejiang University, 2009.

10. R. H. Scanlan, A. Sabzevari. Suspension bridge flutter revisited Preprint No.468, ASCE National Meeting on Structural Engineering, Seattle, May, 1967.

11. Yong Cao, Xiaoguang Yue, Fei Xiong and Youjie Zhao The Software Reliability Model Using Hybrid Model of Fractals and BP Neural Network. IETI Transactions on Computers. 2015.1(1) :11-21 